\title{
DESENVOLVIMENTO DE FRUTOS E GERMINAÇÃO DE SEMENTES DE PHYSALIS ANGULATA L.
}

\section{Francisco dos Santos Neto ${ }^{\mathbf{1}}$; Claudinéia Regina Pelacani ${ }^{2}$; Cristiane Amaral da Silva Ramos ${ }^{3}$; Viviane de Jesus Carneiro ${ }^{4}$.}

1. Graduando em Agronomia, Universidade Estadual de Feira de Santana, e-mail: franciscosantosn@hotmail.com

2. Orientadora, Departamento de Ciências Biológicas, Universidade Estadual de Feira de Santana, e-mail:claudineiapelacani@gmail.com

3. Coorientadora, Universidade Estadual de Feira de Santana, e-mail: crisamaral26@hotmail.com

4. Graduanda em Agronomia e participante do projeto, Universidade Estadual de Feira de Santana, e-mail: vivianedjcarneiro@gmail.com

PALAVRAS-CHAVE: Camapu; germinação; ponto de colheita.

\section{INTRODUÇÃO}

Os frutos de fisális apresentam potencial alimentício e as plantas de algumas espécies tem apresentado grande valor medicinal, especialmente a espécie escolhida nesse estudo Physalis angulata popularmente conhecida como juá-de-capote, camapú, saco-de-bode, dependendo da região onde está inserida. As plantas de $P$. angulata crescem espontaneamente em todo o país, sendo considerada nativa da região amazônica (Moschetto, 2005). Os frutos são reconhecidos por apresentarem um cálice que tem como função protegê-los da ação de insetos e do ambiente (Stehmann et al., 2015), e possuem um grande número de sementes, seu principal meio de propagação (SOUZA et al., 2017).

Por se tratar de uma planta que produz frutos carnosos e sua produtividade ser dependente de condições climáticas, boa disponibilidade hídrica e temperaturas mais amenas, são necessários estudos que possibilitem reconhecer de forma eficiente o ponto de colheita dos frutos cujas sementes apresentem a maior qualidade fisiológica. Isto é, em que momento após a antese o embrião encontra-se desenvolvido e apresente as características máxima de vigor, ou seja, uma emergência sincronizada, rápida e maior porcentagem de plântulas normais. Quando os frutos e sementes apresentam alta qualidade algumas características podem ser observadas e a partir delas será possível caracteriza-las, podendo assim identificar em qual estádio de maturação poderá ser feita a colheita de modo em que não se perca a qualidade fisiológica das sementes.

\section{MATERIAL E MÉTODOS}

Plantas de Physalis angulata foram cultivadas em vasos (10L) que foram dispostos nas linhas com espaçamento de $0,8 \mathrm{~m}$ entre eles e $1,5 \mathrm{~m}$ entre linhas. $\mathrm{O}$ conjunto foi mantido em viveiro coberto com tela tipo sombrite $(50 \%$ de irradiação solar). A irrigação foi feita manualmente, quando necessário. As plantas foram podadas e tutoradas em formato de X, conforme recomendações de Muniz et al (2011). Os tratos culturais e manejo da cultura foram realizados adequadamente e acompanhado diariamente. A partir da antese acompanhou-se o desenvolvimento dos frutos, sendo que após 15, 22, 29, 36, 43 dias após a antese (DAA) foram realizadas coletas e escolhidos aleatoriamente 50 frutos em cada estádio de desenvolvimento. Em laboratório foram separadas as partes do cálice e fruto. Após higienização e secagem com papel toalha a coloração foi comparada utilizando a carta de cores RHS (The Royal Horticultural Society, 2001). Outras avaliações que foram realizadas: peso fresco (g) utilizando balança analítica; diâmetros transversais (medida da região mediana) e longitudinais 
(medida do ápice a base) do fruto $(\mathrm{mm})$ utilizando paquímetro digital; teor de sólidos solúveis totais (SST), em ${ }^{\circ}$ Brix, utilizando refratômetro digital; peso e número de sementes por fruto após a retirada manual da polpa e lavagem das sementes.

Para as sementes foram determinados o conteúdo de água (\%) conforme método descrito na ISTA (2004) submetendo 200 sementes (4 repetições de 50 sementes) a pesagem inicial e após secagem a $103 \pm 2{ }^{\circ} \mathrm{C}$ por $17 \pm 1$ hora. O conteúdo de água e testes de germinação foram realizados com sementes recém coletadas (frescas) em cada estádio de maturação dos frutos e com outrasub amostra de sementes que foram previamente mantidas em ambiente não controlado, sob bancadas, por três dias (secas).

Em cada estádio de desenvolvimento do fruto, sementes frescas e secas foram colocadas para germinar em placas de Petri com 2 folhas de papel germitest ao fundo, umedecidas com quantidade de água equivalente a 2,5 vezes o peso do substrato. Esse conjunto foi mantido por 21 dias em câmaras de germinação com fotoperíodo (12 horas) e temperaturas $\left(20\right.$ e $\left.30{ }^{\circ} \mathrm{C}\right)$ controladas. A emissão da radícula $(2 \mathrm{~mm})$ foi considerada como semente germinada.

Caracterização dos frutos: 10 frutos por repetição, $n=50$. Caracterização das sementes: 50 sementes por repetição, $n=200$. Delineamento utilizado: DIC com fatorial (dia após antese e sementes frescas ou secas).

\section{RESULTADOS E DISCUSSÃO}

Na Tabela 1 são apresentadas as médias referentes às características físicas dos frutos e das sementes coletadas em diferentes estádios de desenvolvimento. É possível observar que ao atingir um maior nível de maturação as características dos frutos como comprimento (C), diâmetro (D), peso fresco (PF), sólidos solúveis totais (SST), e das sementes como o peso de 100 sementes (PS) e do número sementes (NS) por fruto foram os que apresentaram os maiores valores médios..

Tabela 1: Médias do comprimento (C), diâmetro (D), peso fresco (PF), sólidos solúveis totais (SST), peso de 100 sementes (PS) e do número sementes (NS) de frutos em diferentes estádios de desenvolvimento e maturação. UEFS, Feira de Santana, BA, 2018. $\mathrm{N}=50$

\begin{tabular}{lcccccc}
\hline $\begin{array}{l}\text { Dias após } \\
\text { antese }\end{array}$ & $\begin{array}{c}\mathbf{C} \\
(\mathbf{m m})\end{array}$ & $\begin{array}{c}\mathbf{D} \\
(\mathbf{m m})\end{array}$ & $\begin{array}{c}\text { PF } \\
(\mathbf{g})\end{array}$ & $\begin{array}{c}\text { SST } \\
\left({ }^{\circ} \mathbf{B r i x}\right)\end{array}$ & $\begin{array}{c}\text { PS } \\
(\mathbf{m g})\end{array}$ & $\mathbf{N S}$ \\
\hline $\mathbf{1 5}$ & $9,97 \mathrm{~d}$ & $9,26 \mathrm{~d}$ & $0,55 \mathrm{~d}$ & $5,02 \mathrm{~d}$ & $32,08 \mathrm{c}$ & $170 \mathrm{~b}$ \\
$\mathbf{2 2}$ & $11,53 \mathrm{c}$ & $11,30 \mathrm{c}$ & $0,92 \mathrm{c}$ & $6,97 \mathrm{c}$ & $52,48 \mathrm{~b}$ & $183 \mathrm{~b}$ \\
$\mathbf{2 9}$ & $12,42 \mathrm{~b}$ & $12,34 \mathrm{~b}$ & $1,26 \mathrm{~b}$ & $11,00 \mathrm{~b}$ & $54,58 \mathrm{ab}$ & $180 \mathrm{ab}$ \\
$\mathbf{3 6}$ & $13,68 \mathrm{a}$ & $14,42 \mathrm{a}$ & $2,00 \mathrm{a}$ & $11,50 \mathrm{ab}$ & $57,92 \mathrm{a}$ & $222 \mathrm{a}$ \\
$\mathbf{4 3}$ & $14,51 \mathrm{a}$ & $15,52 \mathrm{a}$ & $2,35 \mathrm{a}$ & $11,96 \mathrm{a}$ & $58,70 \mathrm{a}$ & $226 \mathrm{a}$ \\
\hline $\mathbf{C V} \%$ & 3,62 & 3,35 & 9,42 & 3,95 & 4,89 & 7,94 \\
\hline
\end{tabular}

Médias seguidas pela mesma letra na coluna para cada variável analisada não diferem entre si pelo teste de Tukey a 0,05 de significância.

Características como comprimento e diâmetro estão diretamente correlacionados ao desenvolvimento dos órgãos vegetais, refletindo o aumento linear esperado, uma vez que crescimento refere-se ao aumento do numero de células seguido de sua expansão. Consequentemente o tamanho do fruto e o peso se elevam à medida que ocorre 
expansão celular e na diferenciação dos tecidos, ou seja, à medida que os valores de comprimento e diâmetro aumentaram a síntese de componentes celulares e demais macromoléculas também aumentaram. Observou-se ainda que a partir do $36^{\circ}$ dia após a abertura da antese, não houve diferença estatística com os estádios posteriores. Costa et al. (2004) ressaltaram que o peso da massa do fruto e o grau de desenvolvimento estão relacionados. O tamanho e o peso da massa fresca do fruto são características inerentes aos genótipos e deve variar dentro dos limites típicos da variedade (CHITARRA; CHITARRA, 2005). Dentro do esperado o crescimento dos frutos não é continuo e o numero de sementes e o peso atinge valor máximo após 36 DAA.

Como pode ser visto na figura 2 , o peso da massa seca das sementes aumentou de forma rápida nas primeiras fases de desenvolvimento. Segundo Castro et al. (2004), as primeiras fases são definidas pela intensa divisão celular, expansão e deposição de reservas. O aumento do peso seco se mostrou crescente até o 36 DAA, logo após apresentou leve decréscimo. Após as sementes atingirem o acumulo máximo de massa seca elas deixam de receber fotoassimilados e se tornam independentes da planta mãe (Barroso 2015). Diante disso pode-se dizer que esse ponto indica a maturidade fisiológica das sementes, pois corresponde à máxima capacidade de germinação e vigor (MARCOS FILHO, 2005; CARVALHO e NAKAGAWA, 2012).

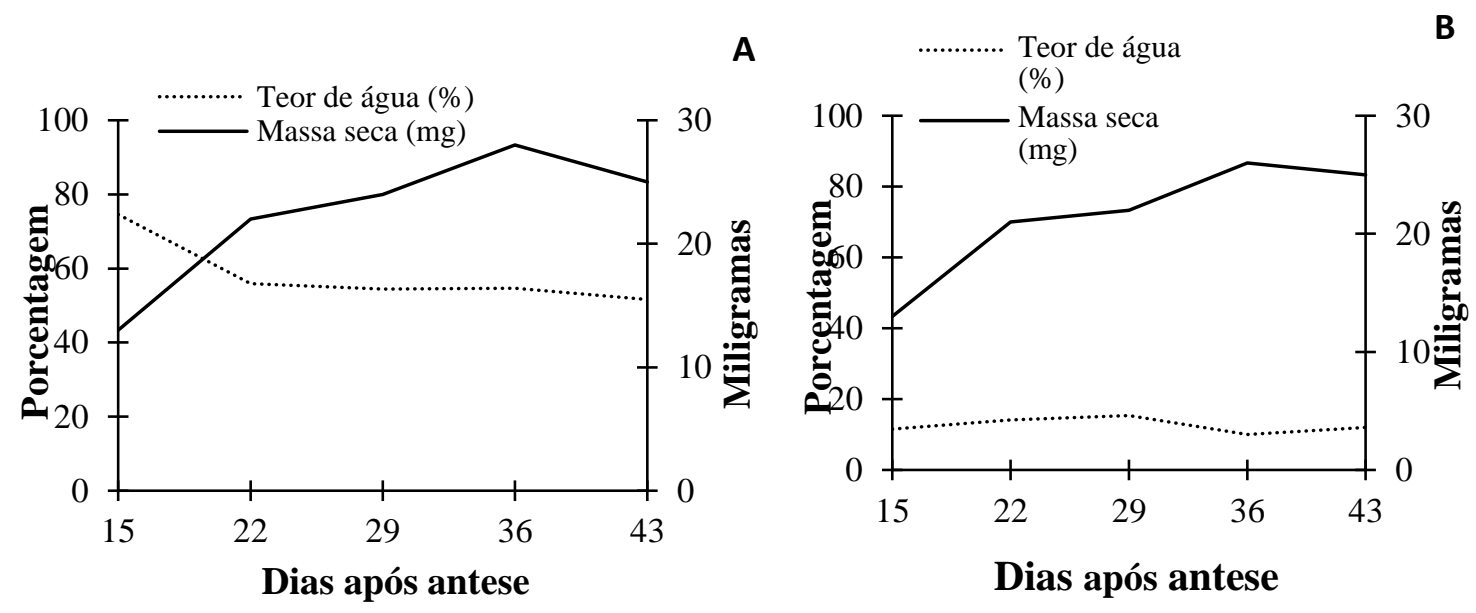

Figura 2: Teor de água e massa seca de sementes frescas (A) e secas (B) nos cinco estádios de desenvolvimento dos frutos de $P$. angulata cultivados na Unidade Experimental Horto Florestal (UEFS), Feira de Santana, Bahia, 2015.

Os teores de água nas sementes foram altos durante todo o período de desenvolvimento, sendo coletadas com \% ainda elevadas (50\%) no ultimo estádio de desenvolvimento. Essa quantidade de água elevada já no período final de desenvolvimento pode ser um agravante para a manutenção da qualidade visto que o metabolismo pode ser considerado ativo e diminuir o conteúdo das reservas, caso as mesmas não percam água até os limites de tolerância após a coleta. O processo de desidratação de frutos carnosos é lento e as sementes ortodoxas apresentam um teor de água entre 30 e 50\% no momento de maturação (CARVALHO E NAKAGAWA, 2012). Caso que ocorreu com a $P$. angulata nesse estudo.

Resultado esperado foi observado quando se adotou o procedimento de dessecação das sementes em bancadas após as coletas. Mesmo sendo uma condição não controlada, as condições do ambiente promoveram a retirada de água das sementes de maneira bastante significativa (Figura 2B), sendo observado conteúdo de água menor de $10 \%$ em todos os estádios avaliados, com pequenas variações. Esse processo de 
dessecação é de fundamental importância para a conservação e para que se obtenham sementes de alta qualidade fisiológica (MARCOS FILHO, 2005; CARVALHO e NAKAGAWA, 2012).

$\mathrm{Na}$ tabela 3 estão demonstrados os resultados referentes à germinação e emergência das sementes provenientes dos frutos coletados nos diferentes estádios de desenvolvimento, onde foi analisado o tempo médio (dias) e a sincronicidade de sementes frescas e secas. Foi possível observar que as sementes quando submetidas à dessecação em ambiente não controlado apresentaram uma maior sincronia (maior valor de Z) tanto nas avaliações de germinação quanto na emergência em campo. O tempo médio (dias-1) também mostrou ser menor, ou seja, quanto menor o tempo, maior a velocidade de emissão das estruturas consideradas de germinação, a radícula, ou de emergência, considerada a emissão e expansão dos cotilédones.

Tabela 3: Tempo médio e sincronicidade de sementes nos 5 estádios de desenvolvimento dos frutos de P. angulata. Horto florestal, Feira de Santana, 2018.

\begin{tabular}{|c|c|c|c|c|c|c|c|c|}
\hline \multirow{4}{*}{ Dias } & \multicolumn{4}{|c|}{ Germinação } & \multicolumn{3}{|c|}{ Emergência } & \\
\hline & \multirow{2}{*}{\multicolumn{2}{|c|}{ Fresca }} & \multirow{2}{*}{\multicolumn{2}{|c|}{ Seca }} & \multirow{2}{*}{\multicolumn{2}{|c|}{ Fresca }} & \multicolumn{2}{|c|}{ Seca } \\
\hline & & & & & & & & \\
\hline & $\overline{\bar{\tau}}($ dias $)$ & $\mathrm{Z}$ & $\bar{\tau}$ (dias) & $\mathrm{Z}$ & $\bar{\tau}$ (dias) & $\mathrm{Z}$ & $\bar{\tau}$ (dias) & $\mathrm{Z}$ \\
\hline 15 & $6,59 \mathrm{~b}$ & $0,25 b$ & 0 & - & 0 & - & 0 & - \\
\hline 22 & $7,38 \mathrm{c}$ & $0,24 b$ & $5,50 \mathrm{c}$ & $0,26 \mathrm{~b}$ & $11,00 \mathrm{~b}$ & $0,34 \mathrm{a}$ & $9,97 b$ & $0,26 \mathrm{~b}$ \\
\hline 29 & $4,52 \mathrm{a}$ & $0,44 a$ & $3,00 \mathrm{a}$ & $0,69 a$ & $8,25 \mathrm{a}$ & $0,41 \mathrm{a}$ & $8,17 \mathrm{a}$ & $0,48 \mathrm{a}$ \\
\hline 36 & $4,86 \mathrm{a}$ & $0,39 a$ & $3,00 \mathrm{a}$ & $0,79 a$ & $8,75 \mathrm{a}$ & $0,28 \mathrm{a}$ & $7,95 \mathrm{a}$ & $0,53 \mathrm{a}$ \\
\hline 43 & $4,94 \mathrm{a}$ & $0,43 \mathrm{a}$ & $4,00 \mathrm{~b}$ & $0,85 \mathrm{a}$ & $11,25 \mathrm{~b}$ & $0,52 \mathrm{a}$ & $7,90 \mathrm{a}$ & $0,52 \mathrm{a}$ \\
\hline
\end{tabular}

\section{CONSIDERAÇÕES FINAIS}

Conclui-se então que os frutos de Physalis angulata atingem tamanho máximo a partir do $36^{\circ}$ dia após a antese quando o cálice apresenta coloração arroxeada para marrom. Quanto a capacidade de germinação, as sementes de $P$. angulata são capazes de emitirem radícula a partir do $29^{\circ}$ DAA. O procedimento de secagem das sementes pode ser indicado quando o objetivo é obter sementes de maior qualidade fisiológica e destinadas para conservação e armazenamento por períodos mais prolongados, recomendando-se ainda que a coleta ocorra aos $43^{\circ}$ DAA por estarem mais maduras fisiologicamente.

\section{REFERÊNCIAS}

BARBEDO, C.J.; MARCOS-FILHO, J. Tolerância à dessecação de sementes. Acta Botanica Brasilica, v. 12, 145-164, 1998.

BARROSO, N. S. Maturação de frutos e viabilidade de sementes de Physalis ixocarpa Brot. ex Hormen. Dissertação (mestrado) - Universidade Estadual de Feira de Santana, Programa de Pós-Graduação em Recursos Genéricos Vegetais, 2015.

CARVALHO, N. M.; NAKAGAWA, J. Sementes: ciência, tecnologia e produção. Jaboticabal, FUNESP, 2012.

CASTRO, R.D. et al. Desenvolvimento de sementes e conteúdo de água. In: Ferreira A.G; Borghetti, F. (orgs.). Germinação: do básico ao aplicado. Artmed, Porto Alegre. 2004. 
CHAVES, M. da C. V. et al. Caracterização físico-química do suco da acerola. Revista de Biologia e Ciências da Terra, Campina Grande, v. 4, n. 2, 2004.

CHITARRA, M. I. F.; CHITARRA, A. B. Pós-colheita de frutos e hortaliças: fisiologia e manuseio Lavras: Ed. UFLA, 2005. 2 ed. revisada e ampliada. 785 p.

MARCOS FILHO, J. Fisiologia de sementes de plantas cultivadas. Piracicaba: FEALQ, 2005.

COSTA, N. P.; LUZ, T. L. B.; BRUNO, R. L. A. Caracterização físico-química de frutos de umbuzeiro (Spondias tuberosa) colhidos em quatro estádios de maturação. Bioscience Journal (Uberlândia), v. 20, n. 2, p. 65-71, 2004.

Stehmann, J.R. et al. 2015. Solanaceae in Lista de Espécies da Flora do Brasil. Jardim Botânico do Rio de Janeiro.

Disponivel em: 〈http://floradobrasil.jbri.gov.br/jabot/floradobrasil/FB14696>. Acesso em: 05 ago. 2019.

SOUZA, C. L. M. et al. Biometric characteristics of fruits and physiological characterization of seeds of Physalis species (Solanaceae). Agrária - Revista Brasileira de Ciências Agrárias ISSN (on line) 1981-0997 v.12, n.3, p.277-282, 2017. 